\title{
DETERMINATION OF THE D AND L CONFIGURATION OF NEUTRAL MONOSACCHARIDES BY HIGH-RESOLUTION CAPILLARY G.L.C.
}

Gerrit J. Gerwig, Johannis P. Kamering, and Johannes F. G. Vliegenthart*

Laboratory of Organic Chemistry, University of Utrecht (The Netherlands)

(Received June 20th, 1977; accepted for publication July 22nd, 1977)

\section{ABSTRACT}

Capillary g.l.c. on SE-30 of the trimethylsilylated (-)-2-butyl glycosides of $D$ and $L$ monosaccharides gives multiple peak patterns, which can be used for the assignment of the absolute configurations. (-)-2-Butyl glycosides can be prepared from monosaccharides or their methyl glycosides; consequently, for the analysis of oligo- or poly-saccharides, hydrolysis as well as methanolysis can be applied. Provided that the peaks of the (-)-2-butyl glycosides do not completely overlap, mixtures of monosaccharides can be analysed directly, as illustrated for the constituents of the cell-wall lipopolysaccharide from Salmonella typhimurium LT-2.

\section{INTRODUCTION}

In structural studies of polysaccharides and glycoconjugates, the absolute configurations of the constituent monosaccharides are usually determined by measurement of the optical rotation or by application of specific enzymes. The former method requires highly purified monosaccharides and substantial amounts of material, and the latter requires specific enzymes that are not always available.

Recently, the use of g.l.c. for the separation of enantiomers ${ }^{1-3}$ has been reviewed. The resolution of racemic mixtures has been achieved by (1) using a chiral stationary phase, and (2) conversion of the enantiomers into diastereomers by a chiral reagent, and separation on a non-chiral phase. The introduction of highresolution capillary columns wall-coated with non-chiral phases has made the latter approach very attractive.

Our results ${ }^{4}$ on the separation of the enantiomeric forms of amino acids and hydroxy acids, as the corresponding (-)-menthyl esters on capillary columns wallcoated with SP-1000, prompted an investigation of $D$ and $L$ sugars. We now describe the resolution of a number of common $D$ and $L$ neutral monosaccharides as the corresponding trimethylsilylated (-)-2-butyl glycosides on capillary columns wallcoated with $\mathrm{SE}-30$ as stationary phase.

\footnotetext{
*To whom correspondence should be addressed.
} 


\section{RESULTS AND DISCUSSION}

Figs. 1-8 show the g.1.c. patterns of the trimethylsilylated (-)-2-butyl glycosides of D- and L-arabinose, L-rhamnose, D- and L-fucose, D-ribose, D- and L-xylose, $D$ - and L-mannose, D- and L-galactose, and D- and L-glucose. The pentoses and 6deoxyhexoses were run isothermally at $150^{\circ}$ and the hexoses at $175^{\circ}$. The (-)-2butanol sample contained $4-5 \%$ of the $(+)$-enantiomer, as shown by the presence



Fig. 1. G.l.c. pattern of trimethylsilylated derivatives of $(a)(-)$-2-butyl D-arabinoside, (b) (-)-2butyl L-arabinoside, and (c) (-)-2-butyl D- + L-arabinoside.

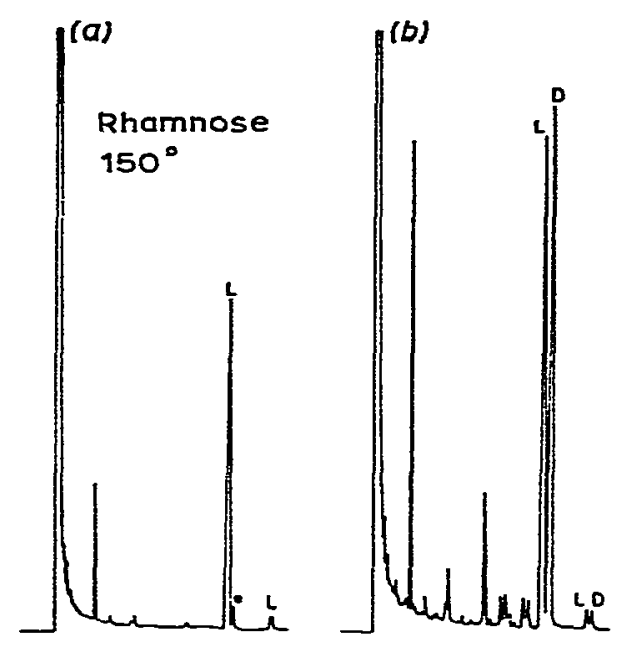

Fig. 2. G.l.c. pattern of trimethylsilylated derivatives of $(a)(-)-2$-butyl L-rhamnoside, and $(b)( \pm)-2$ butyl L-rhamnoside. Because the retention times of the derivatives of $(+)$-2-butyl L-rhamnoside and (-)-2-butyl D-rhamnoside are the same, the peaks in $(b)$ arising from the first derivative have been assigned D. ( \pm )-2-Butanol contained some unknown contaminants with short retention times on SE-30. 


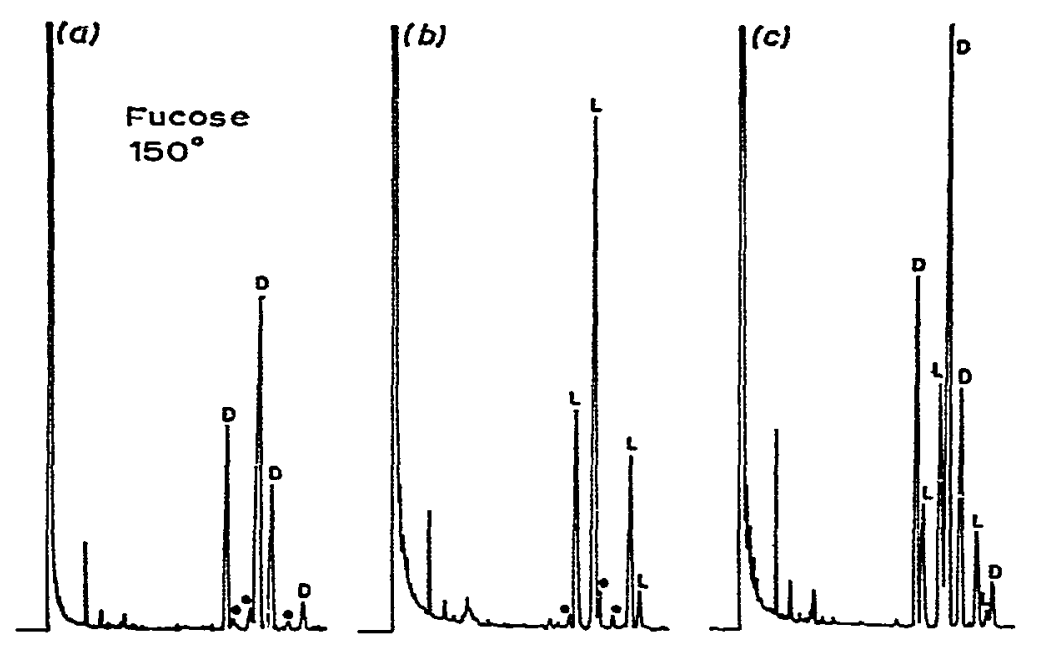

Fig. 3. G.l.c. pattern of trimethylsilylated derivatives of $(a)(-)$-2-butyl D-fucoside, (b) (-)-2-butyl L-fucoside, and (c) (-)-2-butyl D- + L-fucoside.

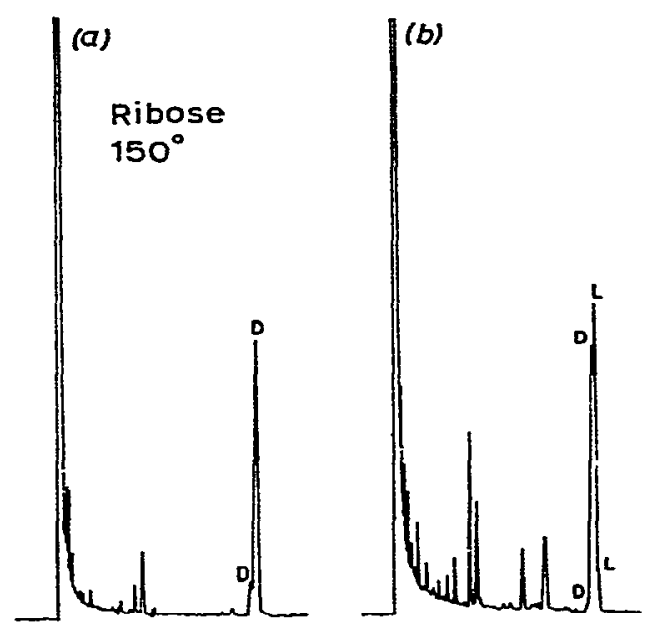

Fig. 4. G.l.c. pattern of trimethylsilylated derivatives of $(a)(-)-2-b u t y l$ D-riboside and $(b)( \pm)-2$ butyl D-riboside. Because the retention times of the derivatives of $(+)-2$-butyl D-riboside and $(-)-2$ butyl $\mathrm{L}$-riboside are the same, the peaks in (b) arising from the first derivative have been assigned $\mathrm{L}$.

of some small peaks marked * in Figs. 2, 3, and 6-8. Sometimes, small proportions $(<4 \%)$ of the free monosaccharides were observed. On non-chiral stationary phases like SE-30, (-)-alkyl D-glycosides and ( + )-alkyl L-glycosides are eluted together, as are (-)-alkyl L-glycosides and (+)-alkyl D-glycosides. This situation was demonstrated by also analysing the $( \pm)$-2-butyl glycosides. The g.l.c. data for D-rhamnose and L-ribose were deduced from the gas chromatograms of the trimethylsilylated (士)-2-butyl glycosides of L-rhamnose and D-ribose, respectively. Fig. 9 shows the gas chromatogram of a mixture of D-and L-fucose, D-and L-xylose, D-and L-mannose, $D$ - and L-galactose, and D- and L-glucose, recorded under programmed conditions 

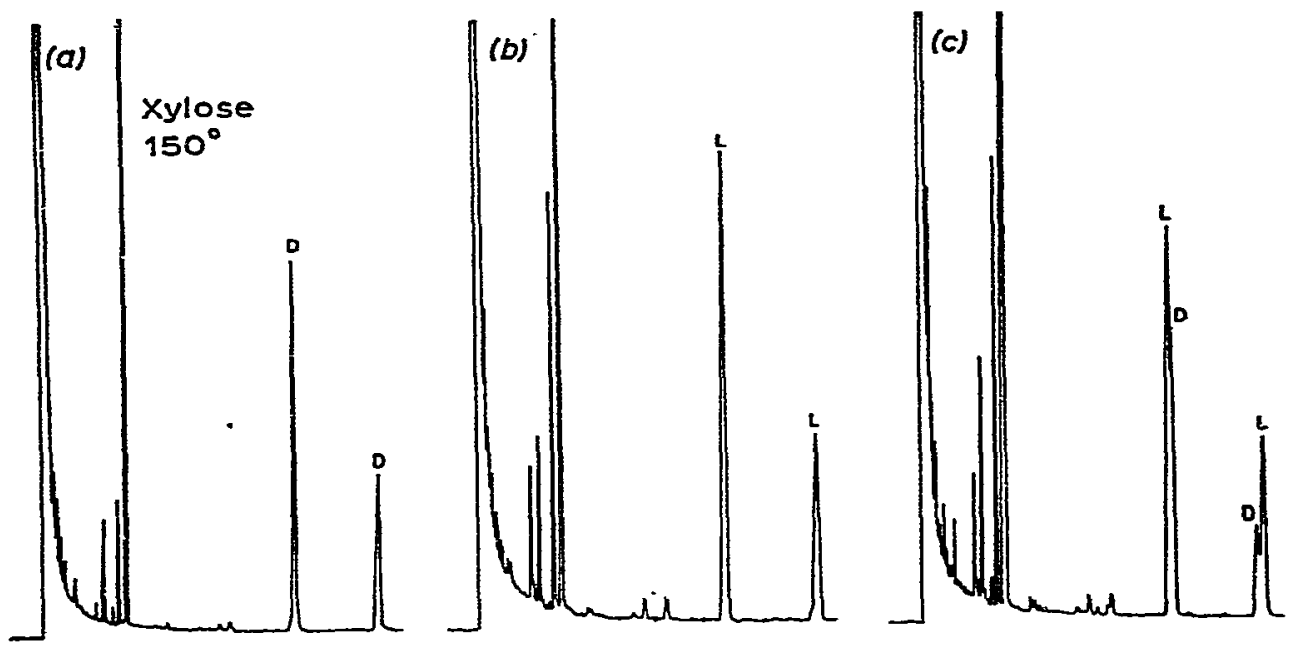

Fig. 5. G.l.c. pattern of trimethylsilylated derivatives of $(a)(-)$-2-butyl D-xyloside, $(b)(-)$-2-butyl L-xyloside, and (c) (-)-2-butyl D- + L-xyloside.

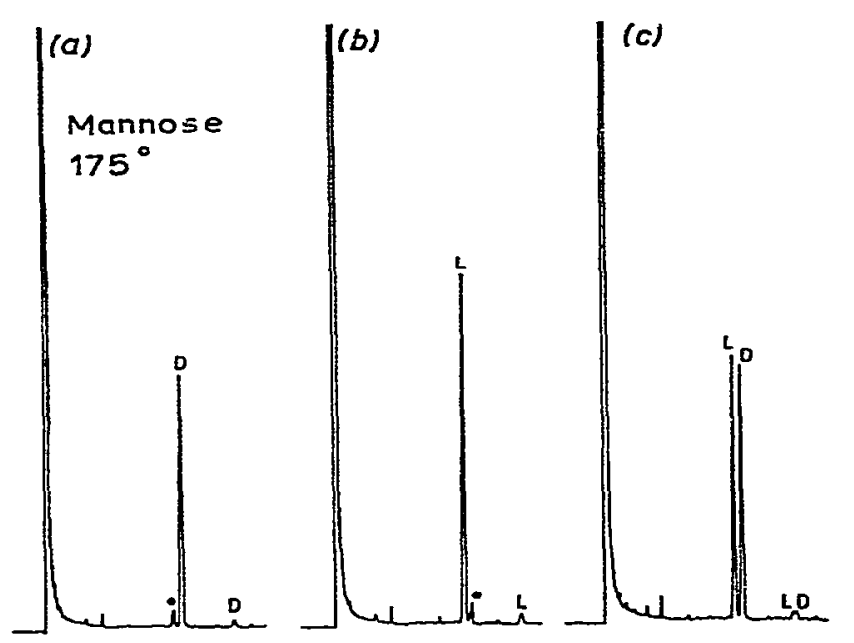

Fig. 6. G.1.c. pattern of trimethylsilylated derivatives of $(a)(-)-2$-butyl D-mannoside, (b) (-)-2butyl L-mannoside, and (c) (-)-2-butyl D- + L-mannoside.

$\left(135^{\circ} \rightarrow 200^{\circ}\right.$ at $\left.1^{\circ} / \mathrm{min}\right)$. Only the main peaks of the different monosaccharides have been indicated.

Table I summarizes the relative retention times $(T)$ of trimethylsilylated $(-)-2-$ butyl glycosides, together with the corresponding peak-area proportions and the mass-spectrometric data used for assignment of the ring size. The separation factors $\left(T_{\mathfrak{D}} / T_{\mathrm{L}}\right)$ of the different anomers vary from 0.93 to 1.05 .

The trimethylsilylated (-)-2-butyl glycosides give the same type of massspectrometric fragmentation as the corresponding methyl glycosides ${ }^{5}$, and the molecular ion $M$ and/or the fragment ion $M-M e$ were detectable. To discriminate be- 


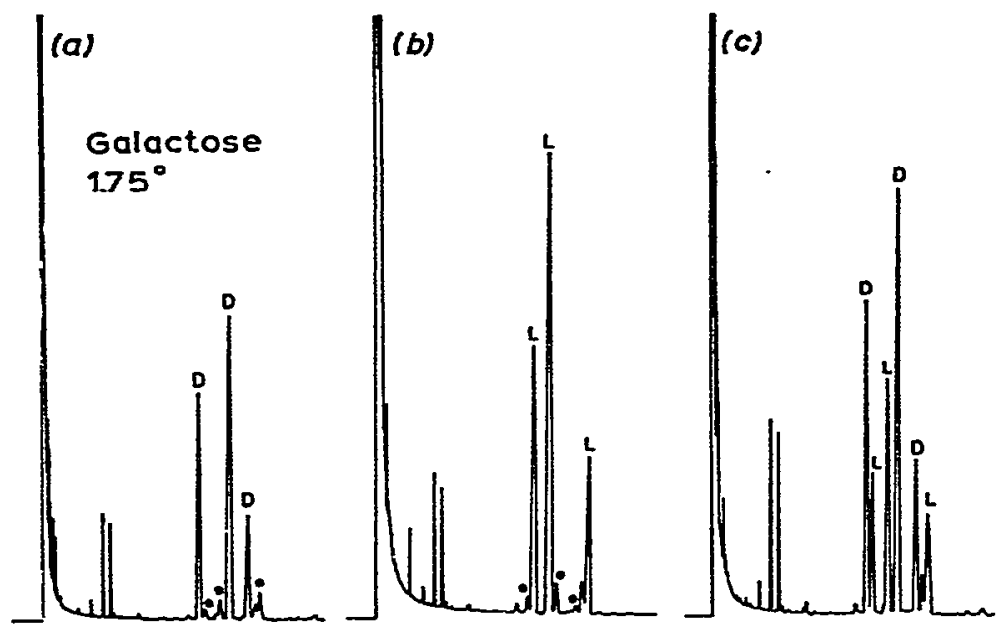

Fig. 7. G.1.c. pattern of trimethylsilylated derivatives of $(a)(-)-2-b u t y l$ D-galactoside, (b) (-)-2butyl L-galactoside, and (c) (-)-2-butyl D- + L-galactoside.

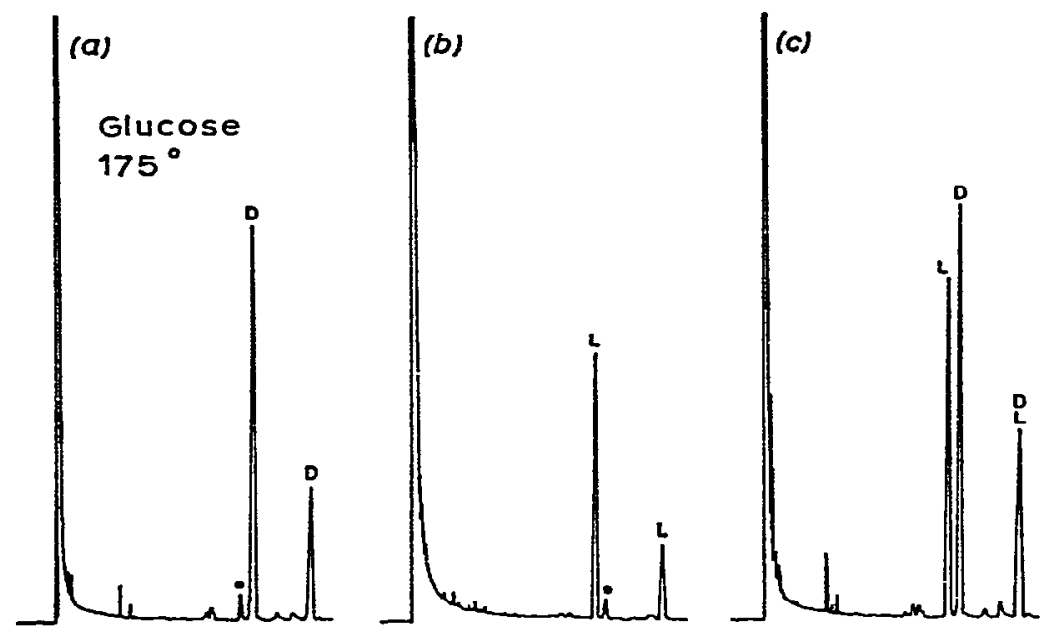

Fig. 8. G.l.c. pattern of trimethylsilylated derivatives of $(a)(-)$-2-butyl D-glucoside, $(b)(-)$-2-butyl L-glucoside, and (c) (-)-2-butyl D- + L-glucoside.

tween pyranoid and furanoid forms, the ratio of the intensities of the peaks at $m / e 204$


or $\mathrm{Me}_{3} \mathrm{SiO}-\mathrm{CH}-\mathrm{CH}\left(\mathrm{OSiMe}_{3}\right.$ )- $\left.\mathrm{C}_{\mathrm{C}}^{+} \mathrm{H}\right]$ was used $^{5}$. For aldohexoses and 6-deoxyaldohexoses, pyranoid forms give a ratio $m / e$ 204/217 $\gg 1$, whereas furanoid compounds show a ratio «1. Moreover, for aldohexoses, the presence of an intense peak at $m / e$ $205\left[\mathrm{CH}_{2} \mathrm{OSiMe}_{3}-\mathrm{CH}=\mathrm{OSSiMe}_{3}\right]$ is also characteristic of a furanoid ring. In aldopentoses, the ratio $m / e$ 204/217 varies from $\simeq 1$ to $>1$ for pyranoid forms and is $\ll 1$ for furanoid forms. The $\alpha$ and $\beta$ configurations of the different anomers were not determined ${ }^{5}$. 


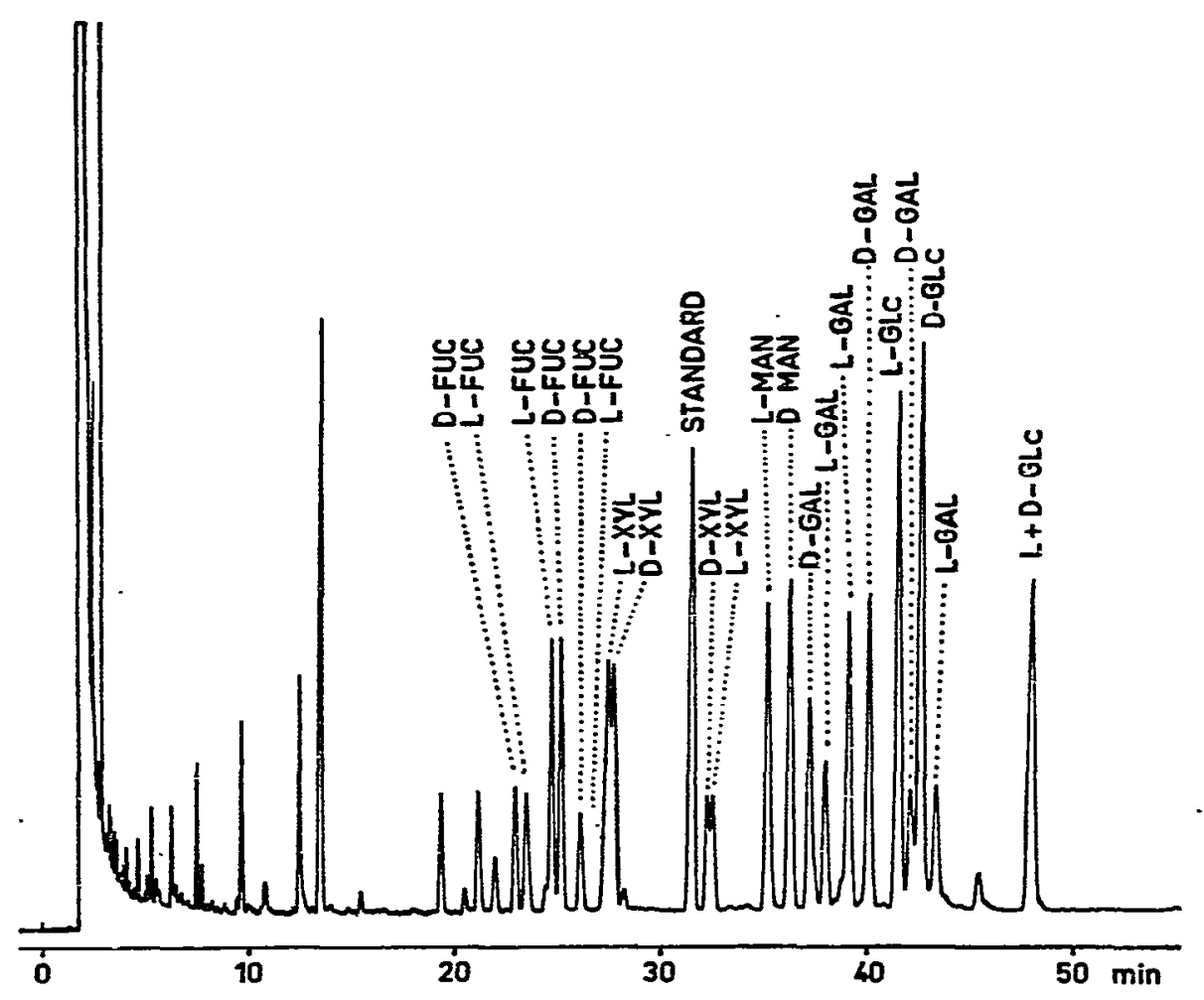

Fig. 9. G.l.c. of trimethylsilylated (-)-2-butyl glycosides of a mixture of $D$ and $L$ monosaccharides (SE-30; temperature programme, $135^{\circ} \rightarrow 200^{\circ}$ at $1 \% \mathrm{~min}$ ).

As is evident from the data in the Figures and Table $I$, the absolute configurations of monosaccharides can be determined easily by g.l.c. of the trimethylsilylated (-)-2-butyl glycosides. Furthermore, Fig. 9 demonstrates the analysis of a mixture of sugars and indicates the applicability of the method to hydrolysates and methanolysates of polysaccharides and glycoconjugates in conjunction with analysis by g.l.c. of the alditol acetates ${ }^{6}$ or trimethylsilylated methyl glycosides ${ }^{7}$. Comparison of g.l.c. data obtained from mixtures of model substances directly butanolysed, or first methanolysed and then butanolysed, showed only insignificant differences in peak intensities.

To illustrate the scope of the method, it was applied to the mixture of rhamnose, mannose, galactose, and glucose obtained from the cell-wall lipopolysaccharide from Salmonella typhimurium LT-2. The polysaccharide was methanolysed and the products were butanclysed and trimethylsilylated. The gas chromatogram (Fig. 10) of the resuiting mixture of trimethylsilylated (-)-2-butyl glycosides demonstrated the occurrence of L-rhamnose, D-mannose, D-galactose, and D-glucose in the polysaccharide, which is in accordance with the literature data ${ }^{8}$.

Preliminary experiments have shown that the procedure is applicable to $N$ acetylhexosamines. 


\section{TABLE I}

G.L.C. AND MASS-SPECTROMETRIC DATA FOR THE TRIMETAYLSILYLATED (-)-2-BUTYL GLYCOSDES OF SOME D AND L MONOSACCHARIDES

\begin{tabular}{|c|c|c|c|c|c|}
\hline \multirow[t]{2}{*}{ Parent sugars } & \multicolumn{2}{|l|}{$\mathbf{T}^{a}$} & \multirow[t]{2}{*}{$\%$} & \multirow[t]{2}{*}{ Mass spectrometry } & \multirow[t]{2}{*}{ Ring size } \\
\hline & $A^{b}$ & $B^{b}$ & & & \\
\hline \multirow[t]{4}{*}{ D-Arabinose } & 0.55 & 0.70 & 47 & $m / e 204 \simeq m / e 217$ & $p^{c}$ \\
\hline & 0.56 & 0.71 & 28 & $m / e 204 \ll m / e 217$ & $f$ \\
\hline & 0.58 & 0.73 & 20 & $m / e 204 \simeq m / e 217$ & $p^{e}$ \\
\hline & 0.67 & 0.80 & 5 & $m / e 204 \ll m / e 217$ & $f$ \\
\hline \multirow[t]{4}{*}{ L-Arabinose } & 0.54 & 0.69 & 31 & $m / e 204 \ll m / e ~ 217$ & $f$ \\
\hline & 0.55 & 0.70 & 43 & $m / e 204 \simeq m / e 217$ & $p^{e}$ \\
\hline & 0.58 & 0.73 & 22 & $m / e 204 \simeq m / e 217$ & $p^{e}$ \\
\hline & 0.70 & 0.82 & 4 & $m / e 204 \ll m / e 217$ & $f$ \\
\hline \multirow[t]{2}{*}{ D-Rhamnosed } & 0.59 & 0.72 & 一 & 一 & $p$ \\
\hline & 0.71 & 0.82 & - & $-=$ & $\boldsymbol{p}$ \\
\hline \multirow{2}{*}{ I-Rhamnose } & 0.57 & 0.71 & 96 & $m / e 204 \gg m / e 217$ & $p$ \\
\hline & 0.70 & 0.81 & 4 & $m / e 204 \gg m / e 217$ & $p$ \\
\hline \multirow[t]{4}{*}{ D-Fucose } & 0.59 & 0.72 & 24 & $m / e 204 \ll m / e 217$ & $f$ \\
\hline & 0.69 & 0.79 & 53 & $m / e 204 \gg m / e ~ 217$ & $p$ \\
\hline & 0.72 & 0.82 & 19 & $m / e 204 \gg m / e 217$ & $p$ \\
\hline & 0.82 & 0.89 & 4 & $m / e 204 \ll m / e 217$ & $f$ \\
\hline \multirow[t]{4}{*}{ L-Fucose } & 0.62 & 0.74 & 21 & $m / e 204 \ll m / e 217$ & $f$ \\
\hline & 0.67 & 0.78 & 57 & $m / e 204 \gg m / e 217$ & $p$ \\
\hline & 0.78 & 0.87 & 18 & $m / e 204 \gg m / e 217$ & $\boldsymbol{p}$ \\
\hline & 0.80 & 0.88 & 4 & $m / e 204 \ll m / e 217$ & $f$ \\
\hline \multirow[t]{2}{*}{ D-Ribose } & 0.62 & 0.75 & 11 & - & n.d.e \\
\hline & 0.64 & 0.76 & 89 & $m / e 204 \simeq m / e 217$ & $p$ \\
\hline \multirow[t]{2}{*}{ L-Ribosef } & 0.65 & 0.77 & - & - & $p$ \\
\hline & 0.66 & 0.78 & - & - & n.d. \\
\hline \multirow[t]{2}{*}{ D-Xylose } & 0.80 & 0.88 & 65 & $m / e 204 \gg m / e 217$ & $p$ \\
\hline & 1.04 & 1.02 & 35 & m/e $204 \gg$ m/e 217 & $p$ \\
\hline \multirow[t]{2}{*}{ L-Xylose } & 0.79 & 0.87 & 67 & $m / e 204 \gg m / e 217$ & $\boldsymbol{p}$ \\
\hline & 1.06 & 1.03 & 33 & $m / e 204 \gg m / e 217$ & $\boldsymbol{p}$ \\
\hline \multirow[t]{2}{*}{ D-Mannose } & 1.24 & 1.15 & 96 & $m / e 204 \gg m / e 217$ & $p$ \\
\hline & 1.64 & 1.34 & 4 & $m / e 204 \gg m / e 217$ & $p$ \\
\hline \multirow[t]{2}{*}{ L-Mannose } & 1.18 & 1.12 & 96 & $m / e 204 \gg m / e 217$ & $p$ \\
\hline & 1.61 & 1.32 & 4 & $m / e 204 \gg m / e 217$ & $\boldsymbol{p}$ \\
\hline \multirow[t]{3}{*}{ D-Galactose } & 1.27 & 1.18 & 31 & $m / e 204 \ll m / e 217 ; m / e 205$ & $f$ \\
\hline & 1.47 & 1.28 & 51 & $m / e 204 \gg m / e 217$ & $\boldsymbol{p}$ \\
\hline & 1.61 & 1.34 & 18 & $m / e 204 \gg m / e 217$ & $p$ \\
\hline \multirow[t]{3}{*}{ L-Galactose } & 1.30 & 1.21 & 27 & $m / e 204 \ll m / e 217 ; m / e 205$ & $f$ \\
\hline & 1.41 & 1.25 & 55 & $m / e 204 \gg m i e 217$ & $p$ \\
\hline & 1.70 & 1.38 & 18 & $m / e 204 \gg m / e 217$ & $p$ \\
\hline \multirow[t]{2}{*}{ D-Glucose } & 1.66 & 1.36 & 71 & $m / e 204 \gg m / e 217$ & $p$ \\
\hline & 2.10 & 1.53 & 29 & $m / e 204 \gg m / e 217$ & $p^{g}$ \\
\hline \multirow[t]{2}{*}{ L-Glucose } & 1.58 & 1.32 & 72 & $m / e 204 \gg m / e 217$ & $\boldsymbol{p}$ \\
\hline & 2.10 & 1.53 & 28 & m/e $204 \gg m / e 217$ & $p^{g}$ \\
\hline
\end{tabular}

aRelative to that of trimethylsilylated methyl $\alpha$-D-galactopyranoside $\left(\sim 26 \mathrm{~min}\right.$ at $150^{\circ}, \sim 10 \mathrm{~min}$ at $\left.175^{\circ}\right){ }^{\circ} \mathrm{A}$, Isothermally: pentoses and 6 -deoxyhexoses at $150^{\circ}$, hexoses at $175^{\circ} ; B$, temperature programmed, $135^{\circ} \rightarrow 200^{\circ}$ at $1 \% \mathrm{~min}$ ( $T$ for the internal standard was $\sim 31 \mathrm{~min}$ ). $=$ The peaks from the pyranoid forms of the $D$ - and $L$-arabinosides were not separated. The ring sizes and $T$ values deduced from g.l.c. and g.l.c.-m.s. data for trimethylsilylated derivatives of (-)-2-butyl L-rhamnoside and ( \pm )-2-butyl $L$-rhamnoside. ${ }^{e B e c a u s e}$ of the coincidence of the minor and major anomer of ( - )-2butyl D-riboside on SE-30 or OV-1, determination of ring size could not be performed by g.l.c.-m.s. The g.l.c. data deduced from trimethylsilylated ( - -2-butyl D-riboside and ( \pm -2-butyl D-riboside. The same holds for the ring size of the main product. TThe peaks originating from the pyranoid forms of the D- and L-glucosides were not separated. 


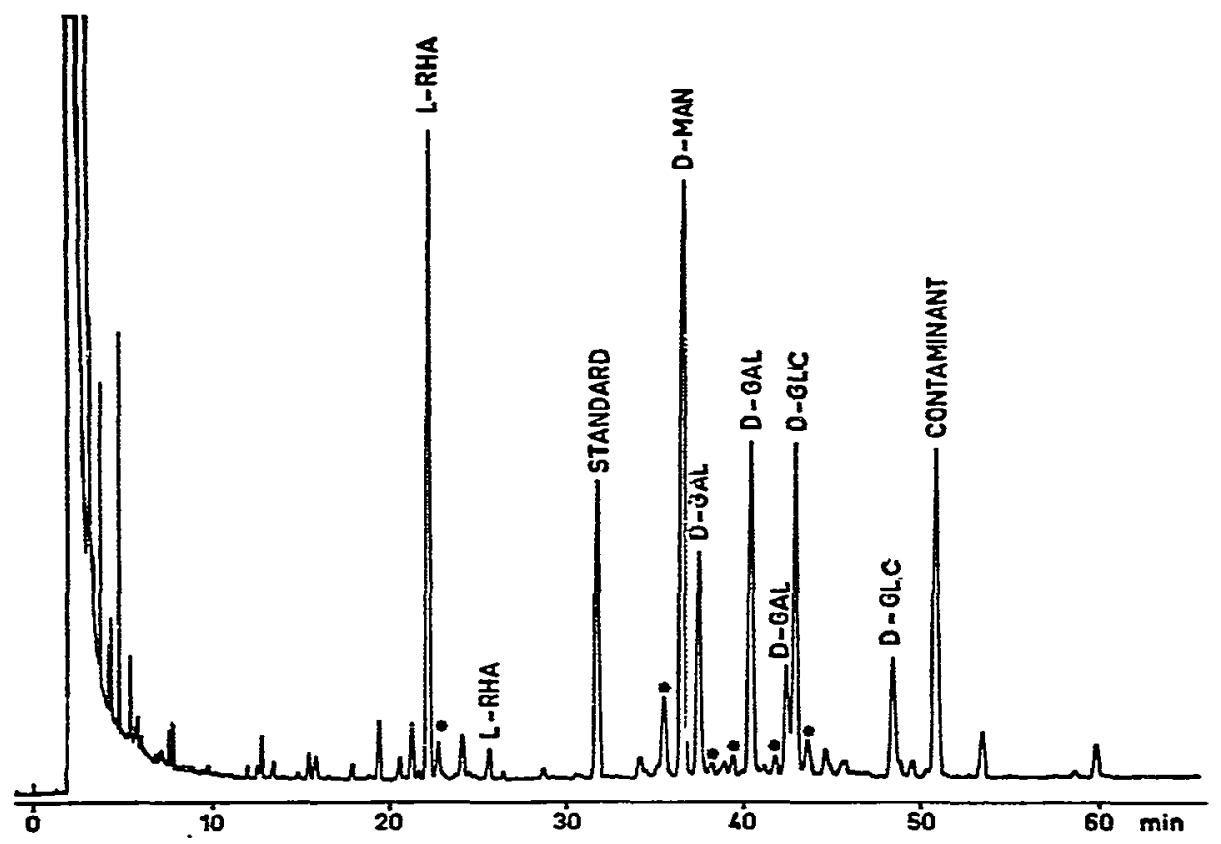

Fig. 10. G.l.c. (see Fig. 9) of the trimethylsilylated (-)-2-butyl glycosides of the monosaccharides occurring in the cell-wall lipopolysaccharide from Salmonella typhimurium LT-2. The peaks marked * originate from the $(+)$-enantiomer in the $(-)$-2-butanol sample.

EXPERIMENTAL

(-)-2-Butanol (purum) was obtained from Fluka AG, and the lipopolysaccharide from Salmonella typhimurium LT-2 was a gift of Dr. J. Lönngren (University of Stockholm).

Alcoholic [(-)- or ( \pm -2-butanol; methanol] solutions of hydrochloric acid were prepared by analogy with Ref. 7 , and stored at $-18^{\circ}$ in a desiccator.

Butanolysis and trimethylsilylation of monosaccharides. - Nitrogen was bubbled through a solution of dry monosaccharide $(0.5 \mathrm{mg})$ in $(-)$ - or $( \pm)$-2-butanolic $\mathbf{M}$ $\mathrm{HCl}(0.5 \mathrm{ml})$ for $30 \mathrm{sec}$, and the ampoule was then sealed. After butanolysis for $8 \mathrm{~h}$ at $80^{\circ}$, the solution was neutralized with $\mathrm{Ag}_{2} \mathrm{CO}_{3}$, the precipitate was triturated thoroughly and centrifuged (2000 $\mathrm{g}$ for $10 \mathrm{~min}$ ), and the supernatant solution was concentrated under reduced pressure at $45^{\circ}$. The residue was dried for $12 \mathrm{~h}$ in vacuo over $\mathbf{P}_{2} \mathrm{O}_{5}$, and then treated with hexamethyldisilazane-chlorotrimethylsilanepyridine $(0.1 \mathrm{ml}, 1: 1: 5)$ for $30 \mathrm{~min}$ at room temperature.

Methanolysis-butanolysis of Salmonella typhimurium LT-2 lipopolysaccharide. The polysaccharide ( $2 \mathrm{mg}$ ) was solvolysed in methanolic $\mathrm{M} \mathrm{HCl}$ for $24 \mathrm{~h}$ at $85^{\circ}$ as reported earlier ${ }^{5}$, except that the re- $N$-acetylation step was omitted. Parts of the mixture of methyl glycosides were analysed quantitatively as the trimethylsilyl derivatives and butanolysed and trimethylsilylated as described above. 
G.l.c. was performed on a Varian Aerograph 2740-30-01 gas chrornatograph equipped with a flame-ionization detector and a glass-capillary column $(25 \mathrm{~m} \times$ $0.31 \mathrm{~mm}$ ) wall-coated with SE-30 (LKB-Produkter A.B., Stockholm). The emptycolumn volume was $1.90 \mathrm{ml}$ and the coating efficiency was $84 \%$. The nitrogen flowrate was $1 \mathrm{ml} / \mathrm{min}$ and the make-up gas flow-rate was $30 \mathrm{ml} / \mathrm{min}$. The injection-port and detector temperatures were $200^{\circ}$ and $220^{\circ}$, respectively. The instrument was operated at $150^{\circ}$ for derivatives of pentoses and 6-deoxyhexoses, and at $175^{\circ}$ for the derivatives of hexoses. For mixtures, the temperature was programmed from $135^{\circ} \rightarrow$ $200^{\circ}$ at $1 \% \mathrm{~min}$. Samples $(0.01-0.10 \mu \mathrm{l})$ were injected directly on the column, without a stream splitter. Peak areas and retention times were determined with a Varian CDS 101 .

Mass spectra (75 eV) were recorded on a Jeol JGC-1100/JMS-07 combination with an ion-source temperature of $250^{\circ}$, an accelerating voltage of $3 \mathrm{kV}$, and an ionizing current of $300 \mu \mathrm{A} ; 3.8 \%$ of SE-30 and $3 \%$ of OV-1 on Chromosorb W/AWDMCS (HP, 80-100 mesh) were used as column materials. The oven temperature of the gas chromatograph was dependent on the type of sample.

\section{ACKNOWLEDGMENTS}

We thank Mr. C. Versluis for recording the mass spectra, and Dr. C. P. J. Glaudemans and Dr. J. Lönngren for generous gifts of L-galactose diethyl dithioacetal and the Salmonella typhimurium LT-2 lipopolysaccharide, respectively. This investigation was supported, in part, by the Netherlands Foundation for Chemical Research (SON) with financial aid from the Netherlands Organization for the Advancement of Pure Research (ZWO).

\section{REFERENCES}

1 E. Gil-Av AND D. Nurok, Adv. Chromatogr., 10 (1974) 99-172.

2 P. HuŠEK AND K. MACEK, J. Chromatogr., 113 (1975) 139-230.

3 C. H. LOChMÜller AND R. W. SOUTER, J. Chromatogr., 113 (1975) 283-302.

4 J. P. Kamerling, G. J. Gerwig, J. F. G. Vlifgenthart, M. Duran, D. Ketting, and S. K. WADMAN, J. Chromatogr., 143 (1977) 117-123.

5 J. P. Kamerling, G. J. Gerwig, J. F. G. Vliegenthart, and J. R. Clamp, Biochem. J., 151 (1975) $491-495$.

6 J. S. Sawardeker, J. H. Sloneker, and A. R. Jeanes, Anal. Chem., 37 (1965) 1602-1604.

7 J. R. Clamp, T. BHATti, AND R. E. Chambers, Methods Biochem. Anal., 19 (1971) 229-344.

8 C.-G. Hellerovist, B. Lindberg, S. Svensson, T. Holme, AND A. A. LindBerG, Carbohydr. Res., 9 (1969) 237-241. 